\title{
Population structure of Opisthorchis felineus (Trematoda) and its second intermediate hosts - cyprinid fishes in the Ob-Irtysh focus of opisthorchiasis, based on allozyme data
}

\author{
O. N. ZHIGILEVA ${ }^{1, *}$, V. V. OZHIRELEV ${ }^{2}$, T. F. STEPANOVA ${ }^{2}$, T. I. MOISEENKO ${ }^{3}$
}

\begin{abstract}
${ }^{1}$ Department of Ecology and Genetics, Tyumen State University, Tyumen, Russia, ${ }^{*}$ E-mail: zhigileva@mail.ru;
${ }^{2}$ Laboratory for Environmental Monitoring of Natural Focal Infections, Tyumen Research Institute of Regional Infection Diseases, Tyumen, Russia; ${ }^{3}$ V.I. Vernadsky Institute of Geochemistry and Analytical Chemistry of RAS, Moscow, Russia, E-mail: moiseenko.ti@gmail.com
\end{abstract}

\begin{abstract}
Summary
Genetic variability of West Siberian populations of Opisthorchis felineus and two species of cyprinid fish, its second intermediate hosts, was studied by isozyme analysis. Low levels of allozyme variation and genetic differentiation in O. felineus from the Ob-Irtysh focus of opisthorchiasis were detected. The proportion of polymorphic loci was $21.1 \%$, the average observed heterozygosity (Hobs) was 0.008 , and expected heterozygosity (Hexp) was 0.052 . For most loci in $O$. felineus deficit of heterozygotes (FIS = 0.7424 ) was observed. A comparison of population genetic structure of fish and parasites showed they were not congruent. Estimates of genetic differentiation of the parasite were smaller than for the fish - its intermediate host. Migration and population structure of the second intermediate hosts do not play an important role in formation of the population-genetic structure of $O$. felineus in the Ob-Irtysh focus of opisthorchiasis.
\end{abstract}

Keywords: Opisthorchis felineus; cyprinid fishes; ObIrtysh river basin; genetic structure of populations; isozymes

\section{Introduction}

In recent years, the population genetic studies of parasites have attracted much attention of researchers. This is not only a practical interest, but also to a large extent the development of new methods of studying the genetic structure of microscopic organisms with poorly studied genome. Significant progress has been made in studying the genetics of trematodes - parasites with complex life cycles, and parthenogenetic reproduction of the larval stages. For some species of trematodes the full sequencing of the mitochondrial genome (Shekhovtsov et al., 2010) and more than $85 \%$ of the transcriptome (Young et al., 2010) are completed. In some cases, the life cycles of trematodes were a model for studying fundamental biological pro- cesses, such as the restructuring of the genome during the passage of different stages and mitotic recombination (Grevelding, 1999; Bayne \& Grevelding, 2003; Semyonova et al., 2005; Be'er, 2005).

Particular attention is paid to trematodes of the family Opisthorchidae, which are pathogenic for humans. Opisthorchiasis is generally caused by $O$. felineus and $O$. viverrini trematodes in Southeast Asia, Central and Eastern Europe. It is estimated that worldwide over 23 million people are infected with $O$. felineus and more than 16 million people with $O$. viverrini, with prevalence rates of 40 to 95 percent in some areas (WHO Report, 1995; Andrews et al., 2008). Large natural focus of opisthorchiasis exists in the Ob-Irtysh basin in West Siberia. Prevalence of this infestation in the local human populations in some areas reaches $80 \%$. The source of infection is known to be the cyprinid fishes, from which the roach, dace, and especially ide play the leading role. At the center of natural focus $100 \%$ of ides infested by metacercariae of $O$. felineus, with the intensity of infection exceeding 1000 larvae per individual fish.

Genetic variability of $O$. felineus was studied using the methods of sequencing the sites of nuclear and mitochondrial genome (Katokhin et al., 2008; Shekhovtsov et al., 2009), polymerase chain reaction (Pauly et al., 2003), and karyotyping (Polyakov et al., 2010). The authors found a low level of polymorphism in the West-Siberian populations of $O$. felineus, although other species of this genus are known to have a wide genetic variability (Sithithaworn et al., 2007; Saijuntha et al., 2007; 2008a, b), influencing the epidemiological situation (Andrews et al., 2008). To study the population structure of $O$. viverrini microsatellites (Laoprom et al., 2010), RAPD-markers (Sithithaworn et al., 2007) and isozyme markers (Saijuntha et al., 2006 a, b) were used. Despite some difficulties in the interpretation of isozyme profiles of parasites (Rannala, 1991; Vilas et al., 2002), isozyme analysis is a valuable method for re- 
solving disputes of systematics and population genetics of parasites (Andrews \& Chilton, 1999; Šnábel et al., 2006). The study of population structure of parasites is not possible without data on genetic subdivision of their hosts. Snails play a major role for parasitism of trematodes, but in some cases, there is the effect of population structure and migrations of the second intermediate hosts for the parasite population structure (Keeney et al., 2007). The aim of this research is a comparative study of population genetic structure of $O$. felineus and their intermediate hosts, the cyprinid fishes, in the Ob-Irtysh focus of opisthorchiasis.

\section{Material and methods}

Fish and O. felineus metacercariae were collected from 9 rivers of the Ob-Irtysh river basin, West Siberia, Russia, during the period November-January 2008 - 2010 (Fig. 1). The roach Rutilus rutilus lacustris Pallas, 1811 (Cypriniformes: Cyprinidae) was obtained from the 11 localities, the ide Leuciscus idus Linnaeus, 1758 (Cypriniformes: Cyprinidae) - from 16 localities. A total of 316 specimens of roach and 331 specimens of ide were surveyed (Table 1). Adult $O$. felineus were obtained by infection of the golden (Syrian) hamster Mesocricetus auratus in the standard vivarium conditions (Loskutova, 1980). A total of 30 hamsters were infected. We used muscles of the fish infected with metacercariae of $O$. felineus, which were collected from the same rivers (8 localities) as an invasive material. Muscle samples of fish, destined for infection, have been delivered to the laboratory in coolers with a temperature of $0 \pm 4^{\circ} \mathrm{C}$. They were then viewed under a microscope to assess the extent of infection, identify the trematodes found to a species level and determine their viability. Muscles containing viable larvae of $O$. felineus, were fed to hamsters, $10 \mathrm{~g}$ of tissue per animal. Three months later, adult flukes were recovered in the liver, washed several times in saline and then frozen in microtubes for subsequent electrophoretic study. The validity of O. felineus identification was confirmed by morphological study. There were collected 192 samples (each containing $1-5$ individuals) of adult $O$. felineus. Additionally we took the samples of liver tissue and the blood of hamsters (infected and not infected) which were used as a control. Tissue samples were stored frozen at $-40{ }^{\circ} \mathrm{C}$. Proteins were extracted in a standard way using Tris- $\mathrm{HCl}$ buffer $(\mathrm{pH} 8.0)$ as follows. The sample was homogenized with a glass rod on the ice in an equal volume of buffer, frozen, thawed, and kept for half an hour at $-4{ }^{\circ} \mathrm{C}$, then the homogenate was centrifuged at $3000 \mathrm{~g}$ per minute 30 minutes at $4{ }^{\circ} \mathrm{C}$. The supernatant was mixed with a solution for the application of proteins on the gel (40\% sucrose solution, mixed with the bromophenol blue dye).

Vertical electrophoresis in $7.5 \%$ polyacrylamide gel (Maurer, 1971) in a continuous Tris-borate-EDTA buffer system (Peacock \& Dingman, 1967) was used for protein separation. Electrophoresis was performed in the following mode: $80 \mathrm{~mA}, 10-12 \mathrm{~V} / \mathrm{cm}$ for 2.5 hours. Histochemical identification of proteins was carried out in accordance with the guidelines (Korochkin et al., 1977; Richardson, 1986). Six enzymes: malic enzyme (ME, 1.1.1.40), lactate

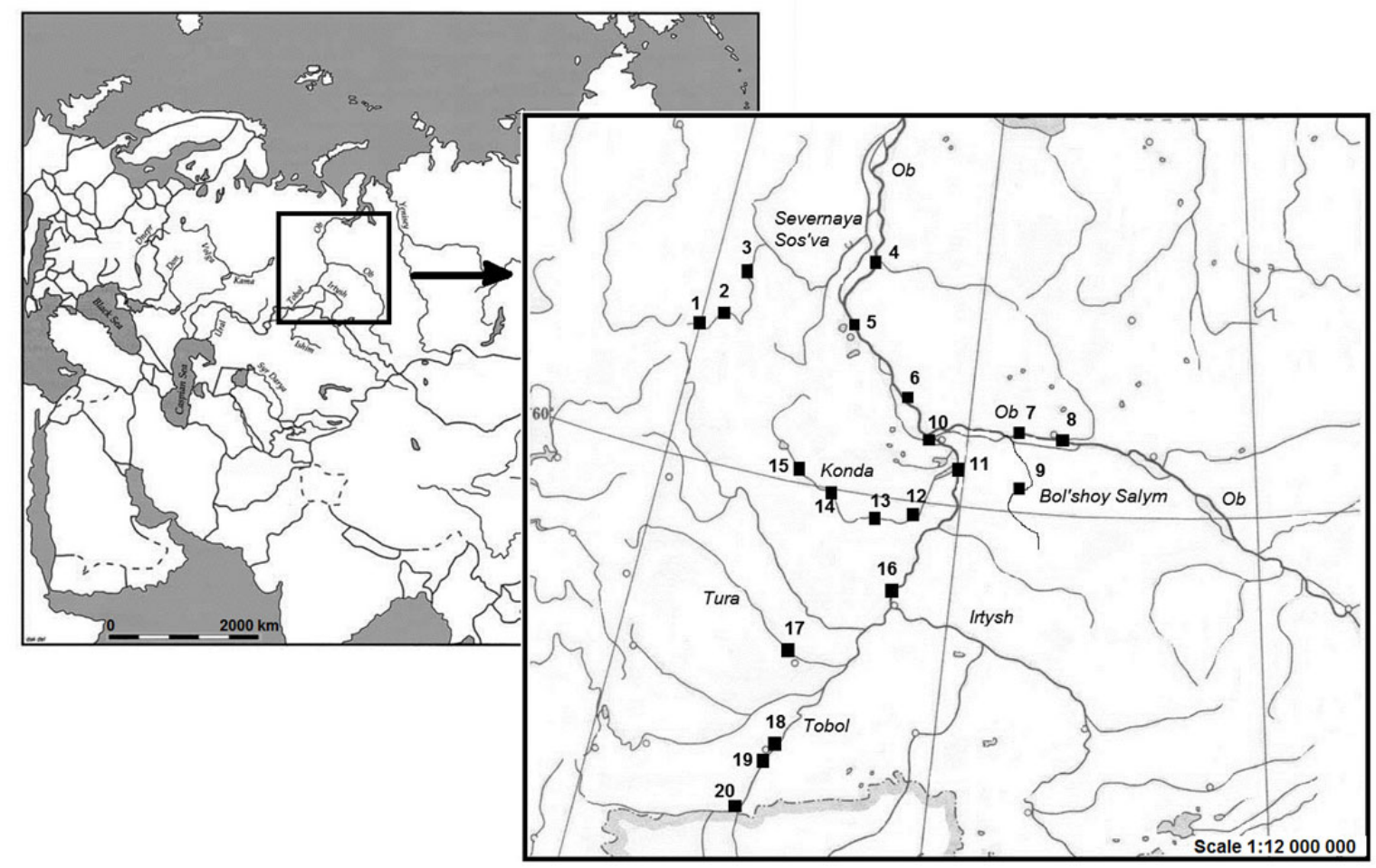

Fig. 1. Places of sample collection: $1-\mathrm{SSp}, 2-\mathrm{SSs}, 3-\mathrm{SSh}, 4-\mathrm{Okm}, 5-\mathrm{Ob}, 6-\mathrm{Ok}, 7-\mathrm{On}, 8-\mathrm{Os}, 9-\mathrm{BSl}, 10-\mathrm{Ihm}, 11-\mathrm{Ik}, 12-\mathrm{Kb}$, $13-\mathrm{Kk}, 14-\mathrm{Km}, 15-\mathrm{Kl}, 16-\mathrm{It}, 17-\mathrm{Tus}, 18-\mathrm{Tk}, 19-\mathrm{Ti}, 20-\mathrm{Tu}$ Geographical localities codes listed in Table 1. 
Table 1. Places of sample collection and the amount of material

\begin{tabular}{|c|c|c|c|c|}
\hline \multirow[t]{2}{*}{ Places of sample collection } & \multirow[t]{2}{*}{ Code } & \multicolumn{3}{|c|}{ Amount of material } \\
\hline & & Ide & Roach & o. felineus \\
\hline Severnaja Sosva River (Village Pugory) & $\mathrm{SSp}$ & 34 & 31 & \\
\hline Severnaja Sosva River (Village Sosva) & SSs & 34 & 34 & 20 \\
\hline Severnaja Sosva River (Village Khulimsunt) & SSh & 30 & 15 & \\
\hline Ob River (Village Kazym Mys) & Okm & 8 & & 21 \\
\hline Ob River (Village Belogorje) & $\mathrm{Ob}$ & 22 & & \\
\hline Ob River (Village Kedrovii) & $\mathrm{Ok}$ & 22 & 8 & \\
\hline Ob River (Nefteyugansk) & On & 8 & 17 & \\
\hline Ob River (Sutgut) & Os & 14 & & \\
\hline Bolshoj Salym River (Village Lyampino) & BS1 & 31 & 32 & \\
\hline Irtysh River (Khanty-Mansijsk) & $\mathrm{Ihm}$ & & & 57 \\
\hline Irtysh River (estuary of Konda River) & $\mathrm{Ik}$ & 18 & & \\
\hline Irtysh River (Village Bolchary) & $\mathrm{Kb}$ & 30 & 30 & \\
\hline Konda River (Village Lugovoj) & $\mathrm{Kl}$ & & & 15 \\
\hline Konda River (Village Kondinskoje) & $\mathrm{Kk}$ & & 30 & 10 \\
\hline Konda River (Village Mezhdurechensk) & $\mathrm{Km}$ & 31 & 30 & 15 \\
\hline Irtysh River (Tobolsk) & It & 18 & & 20 \\
\hline Tura River (Village Sazonovo) & Tus & 10 & & 34 \\
\hline Tobol River (Kurgan) & $\mathrm{Tk}$ & 12 & 38 & \\
\hline Ik River (tributary of the Tobol River in Kurgan area) & $\mathrm{Ti}$ & & 51 & \\
\hline Uj River (tributary of the Tobol River in Kurgan area) & $\mathrm{Tu}$ & 9 & & \\
\hline Total & 20 & 331 & 316 & 192 \\
\hline
\end{tabular}

dehydrogenase (LDH, 1.1.1.27), aspartate aminotransferase (GOT, 2.6.1.1), superoxide dismutase (SOD, 1.15.1.1), nonspecific esterase (EST, 3.1.1.n) and myogenes, were studied both in the parasites and the hosts.

According to the results of electrophoretic analysis the allele frequencies, proportion of polymorphic loci $(P)$, indicators of the mean observed (Hobs) and expected heterozygosity (Hexp), the indices of Nei's genetic identity (INei) and Nei's genetic distance (DNei) (Nei, 1972), Fstatistics was calculated using the PopGen32 software (Yeh et al., 1999). Dendrograms were constructed on the basis of Nei's genetic distance using Unweighed PairGroup method with the Arithmetic average (UPGMA) and the same software. A Mantel test (Mantel, 1967) was used to estimate the correlation between geographic and genetic distance matrices within each species. A nonparametric one-tailed Wilcoxon test was used to compare interpopulation genetic distances of fish and O. felineus.

\section{Results}

Such enzymes as LDH, ME and GOT in O. felineus appear on electrophoregrams in the form of an invariant band. These loci are monomorphic in $O$. felineus, whereas in $O$. viverrini they were found polymorphic (Saijuntha et al., 2007). Myogenes presented six bands on electrophoregrams, all of them were also monomorphic in $O$. felineus. Nonspecific esterases showed 8 zones, 2 of them were polymorphic. Three alleles were recorded at the EST-5 locus and rare electrophoretic variants at the EST-2 locus. The remaining bands were completely invariant in all samples and regions. Superoxide dismutase on electrophoregrams was represented by two zones, differing in activity, and corresponds to the two loci. Locus SOD-1 has lower activity. At this locus, two individuals had a unique electrophoretic mobility associated with the faster allele. The remaining samples were monomorphic and identical. 
Table 2. Allele frequencies of polymorphic isozyme loci in Opisthorchis felineus

\begin{tabular}{lccccccccc}
\hline \multirow{2}{*}{ Locus } & Allele & \multicolumn{7}{c}{ Geographical localities a } \\
\cline { 3 - 10 } & & SS & Okm & Kk & Km & Kl & Tus & Ihm & It \\
\hline EST-2 & 100 & 1.000 & 0.952 & 1.000 & 1.000 & 1.000 & 1.000 & 0.982 & 1.000 \\
& 112 & 0 & 0.047 & 0 & 0 & 0 & 0 & 0.018 & 0 \\
& & & & & & & & & \\
EST-5 & 100 & 0.750 & 0.952 & 0.400 & 0.400 & 0.433 & 0.029 & 0.886 & 0.175 \\
& 92 & 0.250 & 0.048 & 0.550 & 0.500 & 0.567 & 0.971 & 0.114 & 0.825 \\
& 115 & 0 & 0 & 0.050 & 0.100 & 0 & 0 & 0 & 0 \\
SOD-1 & 100 & 1.000 & 0.952 & 1.000 & 1.000 & 1.000 & 1.000 & 1.000 & 0.950 \\
& 150 & 0 & 0.048 & 0 & 0 & 0 & 0 & 0 & 0.050 \\
& & & & & & & & & \\
SOD-2 & 100 & 1.000 & 1.000 & 1.000 & 0.400 & 0.667 & 0.721 & 1.000 & 1.000 \\
& 95 & 0 & 0 & 0 & 0.600 & 0.333 & 0.279 & 0 & 0 \\
\hline${ }^{a}$ Geographical localities codes listed in Table 1 & & & & & &
\end{tabular}

At the polymorphic SOD-2 locus, two alleles were detected in three of 8 surveyed localities.

We identified 19 loci in O. felineus, from them 15 (EST-1, EST-3, EST-4, EST-6, EST-7, EST-8, GOT, LDH, ME, 6 of myogenes) were monomorphic and uniform in all studied samples. Allele frequencies of polymorphic isozyme loci of $O$. felineus from different rivers of the Ob-Irtysh basin are presented in Table 2. The most polymorphic sample was from the $\mathrm{Ob}$ River, where variability was found in 3 loci (EST-2, EST-5, SOD-1). The samples from the rivers Severnaya Sosva and Konda had only one polymorphic locus (EST-5). In the remaining samples the variability was found in 2 loci: EST-5 and SOD-2 or SOD-1. Genetic features of $O$. felineus from the $\mathrm{Ob}$ River are the presence of rare alleles at loci EST-2 and SOD-1. These alleles have a limited distribution and, beside the $\mathrm{Ob}$ River, are found

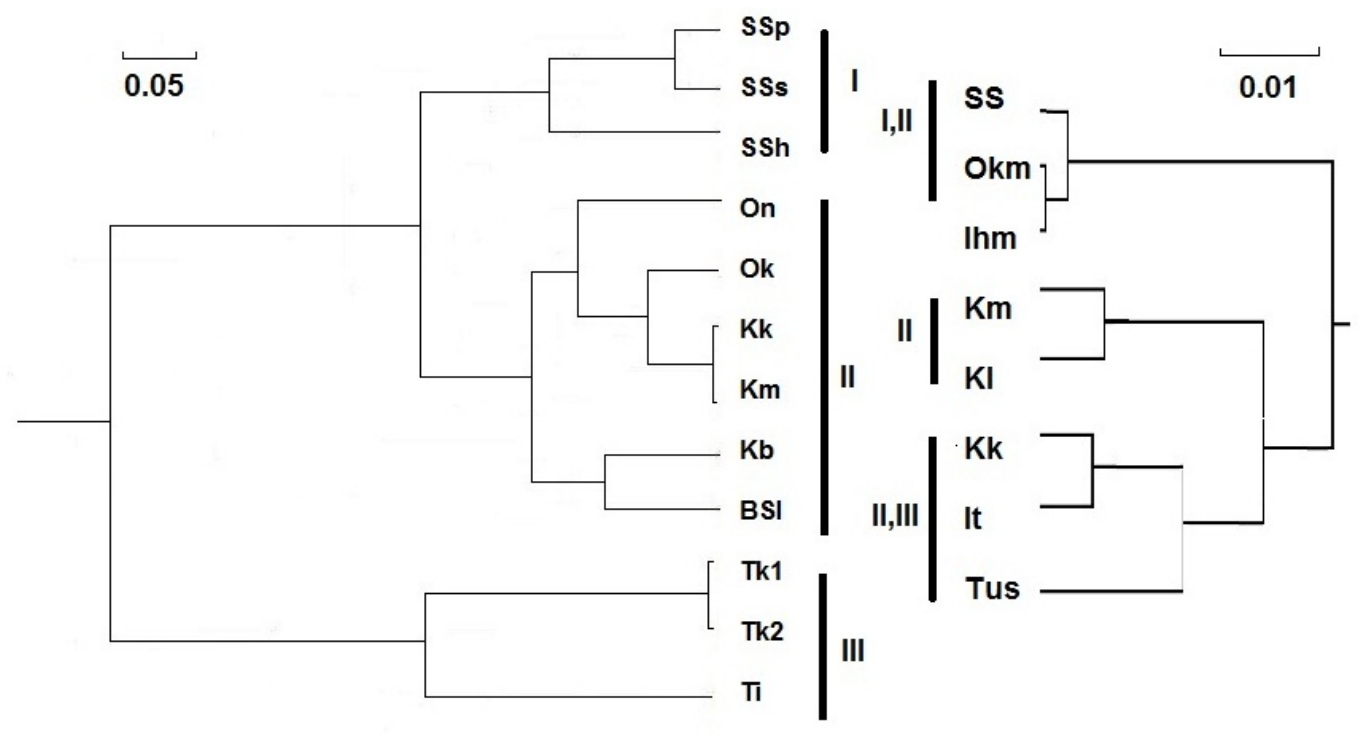

Rutilus rutilus

Opisthorchis felineus

Fig. 2. Tree obtained by UPGMA clustering of Nei (1978) genetic distances for roach (a) and Opisthorchis felineus (b) from different geographical localities of the Ob-Irtysh basin. Geographical localities codes listed in Table 1. 
only in the trematodes from the Irtysh River, where they are rare too. Genetic characteristics of $O$. felineus from the river Konda is a polymorphism at the locus $S O D-2$, the presence of 3 alleles at the locus EST-5 and other allele frequencies in comparison with other areas. The fast allele was dominating at this locus in extreme northern areas, whilst a slow allele was prevailing in the south. However in the river Konda the frequency of fast and slow alleles were almost equal.

Low levels of genetic variation were detected in $O$. $f e$ lineus. Only two loci were polymorphic by $95 \%$ criterion and 4 loci $-99 \%$ criterion. The proportion of polymorphic loci was $21.1 \%$ for the entire sample and ranged from 5.3 to $15.8 \%$ in different localities. The average observed heterozygosity (Hobs) was 0.008 , expected heterozygosity (Hexp) was 0.052. For most loci in O. felineus a low frequency of heterozygous genotypes (Table 3 ) and a deficit of heterozygotes $\left(F_{\text {IS }}=0.742>F_{\mathrm{ST}}=0.337\right)$ were observed. Low frequency of heterozygotes was found in the other species of trematodes (Vilas et al., 2003; Laoprom et al., 2010). This can be explained by the Wahlund effect resulting from mixing the genetically heterogeneous groups of fish infested with parasites, as well as a consequence of reproductive patterns involving selfing.

Calculation of Nei's genetic distances showed a low level of genetic differentiation in $O$. felineus brought from different localities of the Ob-Irtysh river basin (Table 4). The indices of genetic identity ranged from 0.931 to 0.999 . The flukes from geographically remote sampling sites, such as Kazym Mys and the Khanty-Mansiysk, were almost identical genetically $(I N e i=0.9995)$. Genetic distance between the most distant points studied (Kazym Mys and Tura) was $7 \%$. Cluster analysis based on allele frequencies allozyme loci allowed us to describe the population structure of $O$. $f e$ lineus in the studied part of its area. The dendrogram shows the division of $O$. felineus populations into two groups (Fig. 2). The first cluster includes the three northern isolates (Severnaya Sosva river, Ob river, Irtysh river at the merging point with the $\mathrm{Ob}$ river). Genetic differentiation between these isolates is very poorly expressed, despite the considerable geographical distances. The second cluster includes the central part of the Ob-Irtysh focus of opisthorchiasis (Tobolsk) and the river Konda. This cluster includes two clusters differentiated from each other at the level of interpopulation differences. One of them consists of two isolates from the upper Konda river, the second one embraces the lower Konda river and Irtysh river. Thus, there are three $O$. felineus populations in the studied part of the area: the northern, upper-Konda and Kondo-Irtysh.

Genetic structure of West Siberian populations of cyprinid fishes has been studied using the same isozyme markers previously (Zhigileva et al., 2010; 2013).

Table 3. Genotype frequencies of polymorphic isozyme loci in Opisthorchis felineus

\begin{tabular}{|c|c|c|c|c|c|c|c|c|c|}
\hline \multirow{2}{*}{ Locus } & \multirow{2}{*}{ Genotype } & \multicolumn{8}{|c|}{ Geographical localities a } \\
\hline & & SS & Okm & Kk & $\mathbf{K m}$ & Kl & Tus & Ihm & It \\
\hline \multirow[t]{3}{*}{$E S T-2$} & $100 / 100$ & 1.000 & 0.905 & 1.000 & 1.000 & 1.000 & 1.000 & 0.982 & 1.000 \\
\hline & $112 / 100$ & 0 & 0.095 & 0 & 0 & 0 & 0 & 0 & 0 \\
\hline & $112 / 112$ & 0 & 0 & 0 & 0 & 0 & 0 & 0.018 & 0 \\
\hline \multirow[t]{4}{*}{$E S T-5$} & $100 / 100$ & 0.750 & 0.905 & 0.400 & 0.400 & 0.333 & 0 & 0.859 & 0.150 \\
\hline & $100 / 92$ & 0 & 0.095 & 0 & 0 & 0.200 & 0.059 & 0.053 & 0.050 \\
\hline & $92 / 92$ & 0.250 & 0 & 0.500 & 0.400 & 0.466 & 0.941 & 0.088 & 0.800 \\
\hline & $115 / 92$ & 0 & 0 & 0.100 & 0.200 & 0 & 0 & 0 & 0 \\
\hline \multirow[t]{3}{*}{ SOD-1 } & $100 / 100$ & 1.000 & 0.952 & 1.000 & 1.000 & 1.000 & 1.000 & 1.000 & 0.950 \\
\hline & $150 / 100$ & 0 & 0.048 & 0 & 0 & 0 & 0 & 0 & 0 \\
\hline & $150 / 150$ & 0 & 0 & 0 & 0 & 0 & 0 & 0 & 0.050 \\
\hline \multirow[t]{3}{*}{$S O D-2$} & $100 / 100$ & 1.000 & 1.000 & 1.000 & 0.400 & 0.667 & 0.647 & 1.000 & 1.000 \\
\hline & $100 / 95$ & 0 & 0 & 0 & 0 & 0 & 0.147 & 0 & 0 \\
\hline & $95 / 95$ & 0 & 0 & 0 & 0.600 & 0.333 & 0.206 & 0 & 0 \\
\hline \multicolumn{2}{|l|}{$P, \%^{\mathrm{b}}$} & 5.3 & 15.8 & 5.3 & 10.5 & 10.5 & 10.5 & 10.5 & 10.5 \\
\hline \multirow{2}{*}{\multicolumn{2}{|c|}{$\operatorname{Hobs}(H \exp )^{\mathrm{b}}$}} & 0.000 & 0.013 & 0.007 & 0.014 & 0.014 & 0.014 & 0.003 & 0.007 \\
\hline & & $(0.027)$ & $(0.026)$ & $(0.040)$ & $(0.084)$ & $(0.069)$ & $(0.033)$ & $(0.017)$ & $(0.031)$ \\
\hline
\end{tabular}

\footnotetext{
${ }^{a}$ Geographical localities codes listed in Table 1.

${ }^{\mathrm{b}}$ including other (monomorphic) loci (LDH, ME, GOT, 6 loci of EST, 6 loci of myogenes)
} 


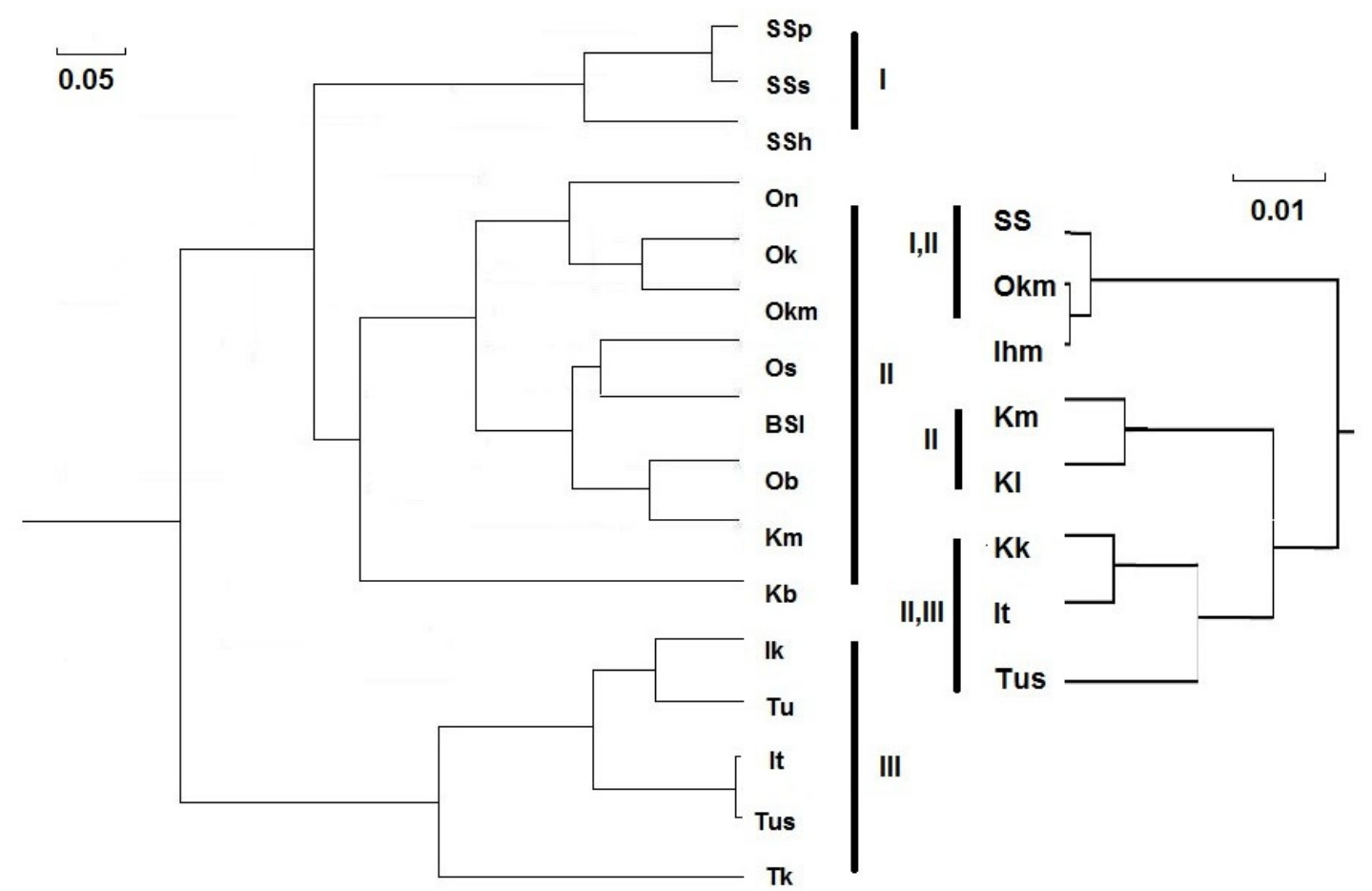

\section{Leuciscus idus}

Opisthorchis felineus

Fig.3. Tree obtained by UPGMA clustering of Nei (1978) genetic distances for ide (a) and Opisthorchis felineus (b) from different geographical localities of the Ob-Irtysh basin. Geographical localities codes listed in Table 1.

Dendrogram based on Nei's genetic distances in the populations of roach shows that this species can be divided into three groups - the southern (Tobolsk), central (middle stream of the $\mathrm{Ob}$ river, Konda river and Bolshoy Salym river) and northern (Severnaya Sosva river), which have considerable specificity of their genetic structure (Fig. 2). Moreover, the southern group of roach (Tobol River and Ik River) is distinct from the others significantly (INei $=$ $0.65)$. The high level of divergence may indicate a different origin of these population groups of roach. The highest rates of genetic identity in Kurgan population of roaches is observed with other samples from the river Tobol, but an index of genetic identity $(\mathrm{INei}=0.83-0.86)$ is too low to classify them as one population.

Ide, as well as roach, is divided into three groups of populations - the southern including the Tobol river, Tura and Irtysh rivers, and the central one, including the river $\mathrm{Ob}$ (middle stream), Konda river and Bolshoy Salym river, as well as the northern one that includes Severnaya Sosva river. The central group of populations genetically closer to the north than to the south, forming with it a common cluster, but with a rather low level of genetic identity

The matrix of genetic identity and distance ${ }^{a}$ in Opisthorchis felineus from different geographical localities of the Ob-Irtysh basin

\begin{tabular}{ccccccccc}
\hline Geographical localities $^{\mathbf{b}}$ & $\mathbf{O k m}$ & $\mathbf{S S}$ & $\mathbf{I h m}$ & $\mathbf{K k}$ & $\mathbf{K m}$ & $\mathbf{K l}$ & $\mathbf{I t}$ & Tus \\
& \multicolumn{1}{c}{} & & & & & & & \\
\hline Okm & - & 0.9968 & 0.9995 & 0.9795 & 0.9554 & 0.9620 & 0.9555 & 0.9313 \\
SS & 0.0032 & - & 0.9989 & 0.9928 & 0.9681 & 0.9851 & 0.9758 & 0.9563 \\
Ihm & 0.0005 & 0.0011 & - & 0.9848 & 0.9608 & 0.9774 & 0.9630 & 0.9407 \\
Kk & 0.0207 & 0.0073 & 0.0153 & - & 0.9753 & 0.9927 & 0.9957 & 0.9831 \\
Km & 0.0456 & 0.0324 & 0.0400 & 0.0250 & - & 0.9967 & 0.9689 & 0.9808 \\
Kl & 0.0284 & 0.0150 & 0.0229 & 0.0073 & 0.0033 & - & 0.9874 & 0.9884 \\
It & 0.0455 & 0.0245 & 0.0377 & 0.0043 & 0.0316 & 0.0127 & - & 0.9928 \\
Tus & 0.0711 & 0.0447 & 0.0611 & 0.0170 & 0.0194 & 0.0117 & 0.0073 & - \\
\hline
\end{tabular}

${ }^{a}$ Above the diagonal - indices of Nei's genetic identity (INei), below the diagonal - Nei's genetic distance (DNei). 
(Fig. 3). Surgut ide is genetically close to ide from the Bolshoy Salym river, which is due to geographical proximity of these items. Ide groups from the rivers Tobol and Tura were genetically very similar, the rate of genetic identity (INei $=0.99)$ indicates that they belong to one population, despite the fact that they live in different rivers. Together with ides from the river Uy, they form a common cluster in the dendrogram, which includes the remaining samples from the rivers Irtysh and Tobol. In each cluster the isolates from different parts of a river are united not due to geography, which indicates a significant role of interpopulation exchange within population groups of fish. Values of Mantel correlation coefficient $\left(R_{\mathrm{M}}\right)$ were low for all of investigated species: in the ide -0.017 , in the roach 0.012 , in $O$. felineus -0.058 . Paired testing of interpopulation genetic distances showed that $D N e i$ for the ide were significantly greater than $\mathrm{DNei}$ for $\mathrm{O}$. felineus based on a nonparametric one-tailed Wilcoxon test $(\mathrm{Z}=3.98, \mathrm{P}=$ 0.00007).

\section{Discussion}

A study of eight isolates of $O$. felineus from different localities of the Ob-Irtysh basin shows that a vast part of the range of this species is characterized by a low genetic diversity at isozyme loci. Samples from geographically remote areas have low values of genetic distances. Nevertheless, there are three population groups of $O$. felineus in the part of the area surveyed. The northern group includes the lower reaches of the $\mathrm{Ob}$ river to the merging point with the Irtysh river and Severnaya Sosva river. It is characterized by the lowest values of genetic distances between isolates of $O$. felineus within this area and significant genetic differences from other groups. The second group, which is called the upper-Konda one, covers a limited area and includes two isolates from the upper Konda river. It is characterized by unique alleles at the locus EST-5, not encountered in other areas, and the unique distribution of allele frequencies of polymorphic loci. The third group includes the isolates from Tobolsk and the Irtysh-Konda confluence. Its genetic peculiarity is the presence of a rare allele at the locus $S O D-1$ (as in the northern group) and a relatively high frequency of the slow allele at the locus $E S T-5$, which is typical for the isolates from Konda. Thus, this group has a mixed ancestry.

Low levels of genetic variation and differentiation in $O$. felineus obtained from other genetic markers (ITS2, CO1, nuclear marker Pm-int9, ISSR) were noted by other authors (Katokhin et al., 2008; Shekhovtsov et al., 2009; Zhigileva et al., 2013a). This may be either due to phylogeographic reasons (the relatively recent and rapid spread of $O$. felineus in the surveyed area from a single source), or environmental reasons - an intense mixing of the gene pool by migration of the hosts. The high frequency of host migration can negate the local adaptation of the parasite (Gandon \& Michalakis, 2002). Low levels of genetic polymorphism of trematodes may be due to other causes related to the characteristics of their population biology: the presence of parthenogenetic phase, contributing to genetic homogeneity, coupled with a sedentary first intermediate hosts, impeding a broad exchange of genes (Be'er, 2005; 1999; Zhigileva, 2007). At the same time, the closely related species $O$. viverrini in Southeast Asia revealed a very high level of genetic differentiation between the provinces, until the fixation of alternative alleles of isozyme loci that allow to suspect the presence of cryptic species (Saijuntha et al., 2006 a, b; Saijuntha et al., 2007). It is unlikely that in closely related species $(O$. felineus and $O$. viverrini), forming a similar parasitic system, the factors determining population differentiation would be different. Low genetic diversity in $O$. felineus can be explained by the Pleistocene glacial events and subsequent sudden population growth from a very limited group of founders (Brusentsov et al., 2013).

Comparison of the population-genetic structures of parasite populations with the population subdivisions of the intermediate hosts, the cyprinid fishes, demonstrated that they were not congruent. The level of genetic differentiation of the parasite is much lower than that of the fish. Lack of strict correlation between genetic distances of the parasite and the hosts was found in other trematode species, the parasites of frogs (Rannala, 1992), of marine fishes (Cribb et al., 2002) and in obligate parasitic unionoid mussel, the parasites of fish in North America (Zanatta \& Wilson, 2011). The genetic population structures of these species were broadly, but not perfectly, congruent. This may be due to facts that host-parasite co-evolution might only partially contribute to the shaping of genetic structure and instead, populations might be often established via localized episodes of host-switching. A variety of historical and temporally independent events may result in alternate adaptive trajectories that differently influence host and parasite gene diversities, along with different rates of protein evolution in hosts and parasites. A strict congruence between the population genetic structure of host and parasite is mostly observed only in the case of highly specific parasites (Thompson, 1994). In our case, O. felineus can use several fish species as intermediate hosts. Consequently, we can conclude that migration and population structure of the second intermediate hosts (fish) does not play an important role in shaping the population genetic structure of $O$. felineus in the studied part of the Ob-Irtysh basin. A possible reason for the low differentiation of populations in $O$. felineus may affect its genetic structure of the final host - humans. Due to large population movements and transport of fishery products, there are the conditions for gene flow in populations of the parasite.

\section{Acknowledgements}

This research was supported by the Federal Target Program "Research and Scientific-pedagogical Cadres of Innovative Russia" for 2009 - 2013, the State Contract P712. 


\section{References}

ANDREws, R. H., Chilton, N. B. (1999): Multilocus enzyme electrophoresis: a valuable technique for providing answers to problems in parasite systematics. Int. J. Parasitol., 9(2): 213 - 253. DOI: 10.1016/S0020-7519(98)00168-4

Andrews, R. H., Sithithaworn, P., Petney, T. N. (2008): Opisthorchis viverrini: an underestimated parasite in world health. Trends Parasitol., 24(11): 497 - 501. DOI: 10.1016/j.pt.2008.08.011

Bayne, C. J., Grevelding, C. G. (2003): Cloning of Schistosoma mansoni sporocysts in vitro and detection of genetic heterogeneity among individuals within clones. $J$. Parasitol., 89: 1056 - 1060. DOI: 10.1645/GE-3186RN BE'ER, S. A. (1999): Some problems of natural foci of human helminthiases in Russia. In: Problems of natural foci. St. Petersburg, pp. $40-56$

BE'ER, S. A. (2005): Biology of the agent of opisthorchiasis. KMK Scientific Press Ltd, Moscow, 336 pp.

Brusentsov, I. I., KAtokhin, A. V., Brusentsova, I. V., Shekhovtsov, S. V., Borovikov, S. N., Goncharenko, G. G., Lider, L. A., Romashov, B. V., Rusinek, O. T., Shibitov, S. K., Suleymanov, M. M., Yevtushenko, A. V., Mordvinov, V. A. (2013): Low genetic diversity in wide-spread Eurasian liver fluke Opisthorchis felineus suggests special demographic history of this trematode species. PLoS ONE, 8(4): e62453. DOI: 10.1371/ journal.pone.0062453

Cribb, T. H., Bray, R. A., Wright, T., Pichelin, S. (2002): The trematodes of groupers (Serranidae: Epinephelinae): knowledge, nature and evolution. Parasitology, 124(7): 23 - 42. DOI: 10.1017/S0031182002001671

GANDON, S., MichalaKis, Y. (2002): Local adaptation, evolutionary potential and host-parasite coevolution: interactions between migration, mutation, population size and generation time. J. Evol. Biol., 15: 451 - 462. DOI: 10.1046/j.1420-9101.2002.00402.x

GREvelding, C. G. (1999): Genomic instability in Schistosoma mansoni. Mol. Biochem. Parasitol., 101: 207 - 216. DOI: 10.1016/S0166-6851(99)00078-X

Katokhin, A. V., Shekhovtsov, S. V., Conco, S., Yurlova, N. I., Serbina, E. A., Vodyanitskaya, S. N., Fedorov, K. P., LokteV, V. B., Muratov, I. V., Ohyama, F., Makhneva, T. V., PelteK, S.E., MordvinOV, V. A. (2008): Assessment of the genetic distinctions Opisthorchis felineus from Opisthorchis viverrini and Clonorchis sinensis by ITS2 and CO1 sequences. Dokl. Biochem. Biophys., 421: 214 - 217. DOI: 10.1134/S1607672908040133

Keeney, D. B., Waters, J. M., Poulin, R. (2007): Diversity of trematode genetic clones within amphipods and the timing of same-clone infections. Int. J. Parasitol., 37(3 4): 351 - 357. DOI: 10.1016/j.ijpara.2006.11.004

Korochkin, L. I., Serov, O. A., Pudovkin, A. I. et al. (1977): Genetics of isoenzymes. Nauka, Moscow, 278 pp. LaOprom, N., Sithithaworn, P., Ando, K., SithithaWORn, J., WongKhama, S., Laha, T., Klinbung, S., Webster, J. P., Andrews, R. H. (2010): Microsatellite loci in the carcinogenic liver fluke, Opisthorchis viverrini and their application as population genetic markers. Infect., Genet. Evol., 10(1): 146 - 153. DOI: 10.1016/j.meegid.2009.11.005

Loskutova, Z. F. (1980): Vivarium. Meditsina, Moscow, $96 \mathrm{pp}$.

MANTEL, N. (1967): The detection of disease clustering and a generalized regression approach. Cancer Res., 27: $209-220$

MAURER, H. (1971): Disk-electrophoresis. Theory and practice of electrophoresis in polyacrylamide gel. Mir, Moscow, 243 pp.

NEI, M. (1972): The genetic distance between populations. Amer. Natur., 106: 283 - 291

Pauly, A., Schuster, R., Steuber, S. (2003): Molecular characterization and differentiation of opisthorchiid trematodes of the species Opisthorchis felineus (Rivolta, 1884) and Metorchis bilis (Braun, 1790) using polymerase chain reaction. Parasitol. Res., 90(5): 409 - 414. DOI: 10.1007/s00436-003-0851-4

Peacock, A. C., Dingman, C. W. (1967): Resolution of multiple ribonucleic acid species by polyacrylamide gel electrophoresis. Biochem., 6: $1818-1827$

Polyakov, A. V., Katokhin, A. V., Romanov, K. V., L'vova, M. N., Mordvinov, V. A., Bocharova, T. A., BoninA, O. M., Yurlova, M. I. (2010): Comparative analysis of karyotypes of Opisthorchis felineus from West Siberia. Contemp. Probl. Ecol., 3(1): 1 - 3. DOI: 10.1134/S1995425510010017

RANNALA, B. (1991): Evidence for host allozymes on electrophoretic gels of trematode parasites (Digenea, Plagiorchiiformes). J. Parasitol., 77: $805-808$

RANNALA, B. (1992): Comparative evolutionary genetics of trematode parasites (Plagiorchiidae) and their anuran hosts. Can. J. Zool., 70: 993 - 1000

Richardson, B. J. (1986): Allozyme electrophoresis. A handbook for animal systematics and Population Studies. Academie Press, London. 410 pp.

SaiJuntha, W., SithithaWorn, P., Wongkham, S., Laha, T., Pipitgool, V., Chilton, N. B., Petney, T. N., ANDREWS, R. H. (2008a): Mitochondrial DNA sequence variation among geographical isolates of Opisthorchis viverrini in Thailand and Lao PDR and phylogenetic relationships with other trematodes. Parasitology, 135: $1479-$ 1486. DOI: $10.1017 / \mathrm{S} 0031182008005015$

SAiJuntha, W., SithithaWORN, P., WONGKhaM, S., LAHA T., Pipitgool, V., Petney, T. N., Andrews, R. H. (2006a): Genetic markers for the identification and characterization of Opisthorchis viverrini, a medically important food borne trematode in Southeast Asia. Acta trop., 100(3): 246 - 251. DOI: 10.1016/j.actatropica.2006.11.001 Saijuntha, W., Sithithaworn, P., WongKham, S., Laha, T., Pipitgool, V., Petney, T. N., Chilton, N. B., ANDREWS, R. H. (2006b): Enzyme markers to identify and characterize Opisthorchis viverrini in Thailand and Laos. Southeast Asian J. Trop. Med. Public Health., 37(3): 43 - 47 Saijuntha, W., SithithaWorn, P., WongKham, S., Laha, T., Pipitgool, V., Tesana, S., Chilton, N.B., 
Petney, T. N., Andrews, R. H. (2007): Evidence of a species complex within the food-borne trematode Opisthorchis viverrini and possible co-evolution with their first intermediate hosts. Int. J. Parasitol., 37: 695 - 703. DOI: 10.1016/j.ijpara.2006.12.008

Saijuntha, W., SithithaWorn, P., WongKham, S., Laha, T., Satrawaha, R., Chilton, N. B., Petney, T. N., ANDREWS, R. H. (2008b): Genetic variation at three enzyme loci within a Thailand population of Opisthorchis viverrini. Parasitol. Res., 103: 1283 - 1287. DOI: 10.1007/s00436-008-1128-8

Semyonova, S. K., Khrisanfova, G. G., Filippova, E. K., BE'ER, S. A., Voronin, M. V., RYSKOV, A. P. (2005): Individual and population variation in cercariae of bird schistosomes of the Trichobilharzia ocellata species group as revealed with the polymerase chain reaction. Rus. J. Genetics, 41(1): $12-16$

Shekhovtsov, S. V., Katokhin, A. V., Kolchanov, N. A., Mordvinov, V. A. (2010): The complete mitochondrial genomes of the liver flukes Opisthorchis felineus and Clonorchis sinensis (Trematoda). Parasitol. Int., 59 (1): 100 - 103. DOI: 10.1016/j.parint.2009.10.012

Shekhovtsov, S. V., Katokhin, A. V., Romanov, K. V., BesprozvanNyKh, V. V., Fedorov, K. P., Yurlova, N. I., Serbina, E. A., Sithithaworn, P., Kolchanov, N. A., Mordvinov, V. A. (2009): A novel nuclear marker, Pmint9, for phylogenetic studies of Opisthorchis felineus, Opisthorchis viverrini, and Clonorchis sinensis (Opisthorchidae, Trematoda). Parasitol. Res., 106: 293 - 297. DOI: 10.1007/s00436-009-1628-1

SithithaWORN, P., NUCHJUNGREED, C., Srisawangwong, T., Ando, K., Petney, T. N., Chilton, N. B., ANDREWS, R. H. (2007): Genetic variation in Opisthorchis viverrini (Trematoda: Opisthorchiidae) from northeast Thailand and Laos PDR based on random amplified polymorphic DNA analyses. Parasitol. Res., 100 (3): 613 - 617. DOI: 10.1007/s00436-006-0304-y

ŠNÁBel, V., MiterpáKOVÁ, M., D’AMElio, S., Busi, M., BArtKovÁ, D., TurČEKOVÁ, L., MADDOX-HytTEl, C., SKUCE, P., DUBINSKÝ, P. (2006): Genetic structuring and differentiation of Echinococcus multilocularis in Slovakia assessed by sequencing and isoenzyme studies. Helminthologia, 43(4): 196 - 202. DOI: 10.2478/s11687-0060037-6

THOMPSON, J. N. (1994): The coevolutionary process. IL: University of Chicago Press, Chicago. 383 pp.
Vilas, R., Paniagua, E., SAnMartín, M. L. (2002): Difficulties in the genetic interpretation of isozyme patterns of Lecithochirium spp. (Trematoda: Digenea). Parasitol. Res., 88(4): 311 - 314. DOI: 10.1007/s00436-001-0522-2

Vilas, R., Paniagua, E., Sanmartín, M. L. (2003): Genetic variation within and among infrapopulations of the marine digenetic trematode Lecithochirium fusiforme. Parasitology, 126(5): 465 - 472. DOI: 10.1017/S0031182003003081

WHO: Control of foodborne trematode infections. Report of a WHO Study Group (1995): World Health Organ. Tech. Rep. Ser., 849: 1 - 157

Yeh, F. C., YAng, R., Boyle, T. (1999): POPGENE, Version 1.31 [computer software]. University of Alberta and Centre for International Forestry Research.

Young, N. D., Campbell, B. E., Hall, R. S., JeX, A. R., Cantacessi, C., Laha, T., Sohn, W.-M., SriPa, B., LOUKAS, A., Brindley, P. J., GASSER, R. B. (2010): Unlocking the transcriptomes of two carcinogenic parasites, Clonorchis sinensis and Opisthorchis viverrini. PLoS Negl. Trop. Dis., 4 (6), e719. DOI: 10.1371/journal.pntd.0000719

ZanatTA, D. T., Wilson, C. C. (2011): Testing congruency of geographic and genetic population structure for a freshwater mussel (Bivalvia: Unionoida) and its host fish. Biol. J. Linn. Soc., 102: $669-685$

ZHigiLEVA, O. N. (2007): The levels of genetic variability of parasites with different life cycle structure. Acta Zool. Lituanica, 17 (2): 129 - 138. DOI: 10.1080/13921 657.2007.10512824

Zhigileva, O. N., OzhiRel'ev, V. V., Brol, I. S., POZHIDAEV, V. V. (2010): Population structure of three fish species (Cypriniformes: Cyprinidae) living in rivers of the Ob-Irtysh basin, by the data of isoenzyme analysis. $J$. Ichthyol., 50(9): 778 - 787. DOI: 10.1134/S003294521009 0110

Zhigileva, O. N., Baranova, O. G., Pozhidaev, V. V., Brol, I. S., MoISEENKo, T. I. (2013): Comparative analysis of using isozyme and ISSR-PCR-markers for population differentiation of cyprinid fish. Turk. J. Fish. Aquat. Sci., 13(1): 159 - 168. DOI: 10.4194/1303-2712v13_1_19

Zhigileva, O. N., Zenovkina, D. V., ZamyatinA, T. A. (2013a): Genetic variability and population differentiation of Opisthorchis felineus (Trematoda) in Western Siberian rivers. Rus. J. Genetics Appl. Res., 3(5): 371 - 377. DOI: $10.1134 / \mathrm{S} 2079059713050122$ 